\title{
Cuando el océano ya no es la última frontera: una relación a (muy) larga distancia a través de las TICs ${ }^{1}$
}

\section{When the ocean is not the final frontier. A (very) long distance relationship through}

Universitat Autònoma de Barcelona JorgeGuillermo.Lewin@campus.uab.es

\section{Resumen}

Se parte del objetivo de comprender las nuevas formas de relación interpersonal a larga distancia que surgen como resultado de las innovaciones tecnológicas. En este material se presenta una autoetnografía de uno de
los investigadores del proyecto "Impacto psicosocial y cultural de las innovaciones tecnocientíficas" (SEC2002-03116) que viajó de Barcelona para cursar su doctorado, dejando en Chile a su mujer. El estudio se centra en la reconstrucción de los procesos implicados en la producción de una nueva forma de relación a larga distancia. Por un lado se refleja el interés por la descripción de estas nuevas formas de interacción social, y por otro se refleja en un interés por los de las innovaciones tecnológicas en la vida diaria.

Palabras clave: Etnografía, Autoetnografía, Keywords: ethnography, autoethnography, new media Tecnologías de la información y la comunicación, technologies, interpersonal relationships, intimacy Relaciones interpersonales, Intimidad

\section{Abstract}

This study aims to understand the new forms of long distance interpersonal relations that emerge as a result from innovations of information and communication technologies (ICT's). This project centres on an autoethnography of one of the researchers who travelled to Barcelona to undertake a doctorate, leaving his wife back home in Chile. The study focuses on the reconstruction of the processes involved in the production of a new form of long distance interpersonal relationship. On one hand, it reflects an interest in the very description of these new forms of social interaction, and on the other, on an interest in the processes that lead towards the stabilization/naturalization of technological innovations in daily life.

${ }^{1}$ Este trabajo se ha realizado en el marco de la investigación "Impacto psicosocial y cultural de las innovaciones tecnocientíficas" (SEC-2002-03116) financiada por el Ministerio de Educación y Ciencia del Gobierno de España. 


\section{Previa}

Este material ${ }^{1}$ está relacionado con las relaciones sociales y las innovaciones tecnocientíficas dentro de las tecnologías de la información y la comunicación (TIC). El objetivo es aportar algo de luz sobre como las TIC se están incorporando en la rutina diaria de las relaciones sociales entre las personas y entre las personas y la tecnología. Con este propósito se ha realizado una etnografía que puede dar alguna cuenta del desarrollo de estas nuevas formas de relación social. En concreto se ha recurrido a uno de los géneros posibles de la etnografía, la autoetnografia. En ella aparece el desarrollo de una forma singular de relación social entre un estudiante de doctorado chileno, el autor, que ha estado viviendo en Barcelona, Cataluña, durante dos años y medio y su mujer que durante todo este tiempo ha permanecido en Chile trabajando.

Se escogió una metodología cualitativa como es la etnografía porque asumimos que la mejor estrategia para el análisis de grupos humanos consiste en establecer relaciones sociales con las personas que forman estos grupos (Velasco, 1997). En este caso una autoetnografia es una forma de auto-narrativa que sitúa el si mismo en el interior de un contexto social determinado (Reed-Danahay, 1997). La autoetnografia es un caso especial de etnografía en el cual el trabajo de campo se confunde con el trabajo de escritura fundiéndose en un mismo acto. Este alto grado de implicación personal, lejos de constituir un problema, un riesgo o un sesgo para la generalización, nos permite entender como se integran las TIC en las múltiples caras de la rutina diaria. Cuando el autoetnógrafo nos muestra sus reflexiones, sus cuestiones, sus dudas, sus interpretaciones, nos permite asistir frente a frente a las diversas formas en que las TIC entran en nuestra cotidianeidad. La historia que el autoetnógrafo escribe nos permite entrar en conversación con él, casi en pie de igualdad, porque nos muestra sus conflictos, sus vulnerabilidades, sus opciones y sus valores. En la autoetnografia se exponen la ambigüedad de nuestras emociones, los múltiples niveles de nuestra experiencia y nuestras incertidumbres. Aunque por supuesto el punto crucial es reflexionar sobre qué hacen estas narrativas, qué consecuencias tienen y qué usos se les puede dar.

\section{Introducción}

Esto de recordar parte de mis vivencias mientras he estado estudiando en Barcelona en estos dos últimos años y medio ha significado internarme en todo un conjunto de experiencias en las que mi compañera ha estado ausente. Esto ha significado rememorar uno de los aspectos que más me ha costado de todo este periplo, y que ha estado constantemente marcado por una sensación de ambivalencia. He vivido muchas experiencias, muy variadas, hermosas, desilusionantes e interesantes, pero nunca las he podido compartir con la mujer que amo más allá de lo que me ha permitido trasmitirle por teléfono. Y como cada verano he viajado a "invernar" mis vacaciones, he sentido que si bien es cierto el contacto telefónico nos ha permitido mantener un cierto contacto e imaginarnos lo que está sucediendo, la vida cara a cara es otra cosa, tiene innumerables matices y con implacable crudeza te vas enterando de lo que ha ido sucediendo.

Nunca imaginé que estos recuerdos serían protagonistas de un trabajo que está directamente relacionado con lo que aquí estudio. $Y$ aunque parezca una obviedad, mis interacciones interpersonales también forman parte de esta vida cotidiana. Siempre he leído con interés las diversas áreas de estudio que se ha dedicado a estudiar cómo funciona la vida cotidiana. Pero, oh sorpresa, una parte mi cotidianeidad será presentada por este trabajo. Siento una sensación de 
sorpresa, de alegría y de cierto honor. Es que resulta que desde hace mucho tiempo que me he sentido especialmente atraído por la belleza de lo simple y siento que adentrarse en mostrar cómo opera lo cotidiano, me resulta simplemente hermoso.

Mientras escribo he sentido un palpitar sonoro, una sensación de nudo en la garganta, de contar cómo he vivido todo esto desde la relación que mi compañera y yo hemos ido construyendo. De cierta manera, hemos llegado a construir una forma de estar presentes donde, de hecho, no lo estamos; donde nuestras respectivas vidas siguen transcurriendo en paralelo, pero finamente unidas por esta peculiar forma de relacionarnos. En cierta medida, al escucharnos a diario, hemos logrado plegar el tiempo, a pesar de las diferencias horarias en que vivimos; hemos logrado plegar la distancia, a pesar de nuestras respectivas ausencias.

Siento que los grandes protagonistas de estas historia son nuestras respectivas voces, la entonación, las inflexiones, los énfasis, los gestos, los silencios, las sutilezas o detalles que sólo dentro de nuestra relación tienen sentido. Nuestras respectivas mismidades son vaciadas a través de nuestras voces, por tanto, tanto el uno como el otro tiene la posibilidad de reconstituir a su interlocutor. Siento mucho fastidio cuando la comunicación se escucha con interferencias o con aquel zumbido, que nebuliza la voz, dejando casi monocorde. Es como no haber hablado con ella y me quedo con una extraña sensación, así como de rabia y frustración.

A continuación veremos cómo se llegó a decantar esta manera de comunicarnos, cómo y por qué fueron descartándose alternativas que también podrían haberse utilizado.

\section{Acerca de nuestra experiencia en el chat.}

La primera forma de comunicarme con mi compañera fue el correo electrónico. En una de las cartas le propuse que chateáramos y viéramos que tal se sentía: ...hoy viernes vamos a chatear, camino expectante y rápido desde la Vila Universitaria hasta la sala de informática de mi facultad. Expectante de conversar con ella y de sentir eso de que la respuesta aparezca rápidamente; nervioso por la utilización del chat, que hacía mucho tiempo que no utilizaba. Por medio del correo electrónico nos habíamos puesto de acuerdo que cada viernes chatearíamos, por lo menos hasta que yo conociera mejor cómo funcionaba la telefonía internacional. Llevaba algo más de una semana en Barcelona y no conocía a casi nadie. Todavía no empezaban los cursos que yo había seleccionado y las clases de catalán recién habían comenzado. Acordamos que serían los viernes, pues ese día era el único día que no tenía clases de catalán. Por la diferencia horaria, cuatro horas, era mejor comunicarnos cuando ella se levantara, ya que de esa forma, podría conectarse a Internet en horario económico. Por la noche era imposible, pues yo tendría que estar conectado a la medianoche para que ella pudiera conectarse en el horario económico. A las diez y quince minutos, hora de España, las seis y quince minutos, hora de Santiago de Chile, ambos teníamos que estar conectados. Los días anteriores había estado conociendo los ordenadores de la sala de informática de mi facultad, para así familiarizarme con el chat, había creado una sala para chatear y había comenzado a buscar alguna página web desde la cual pudiera enviar fax a Chile, ya que mi mamá no tenía correo electrónico, sólo había fax en la administración del edificio donde ella vive.

Aquel viernes había llegado más temprano para asegurarme de tener un ordenador antes que la sala se colapsara de alumnos. Había llegado a las ocho y media, justo cuando se abre la sala. Mientras llegara la hora de la conexión, haría tiempo contestando correos, revisando la prensa online de mi 
país y buscando aquel sitio web desde el cual pudiera enviar faxes a Chile que todavía no lo encontraba.

Mi compañera y yo habíamos acordado chatear a través de la página de emol.com. Ninguno de los dos la habíamos utilizado nunca, sólo nos habían comentado que era fácil utilizarla. Cerca de la hora mi palpitar era muy sonoro, había cargado la página de emol.com con demasiada anticipación. Todavía faltaban algunos minutos, a esa hora ella está recién despertando. Hasta que la conexión se hizo efectiva, un ícono apareció al costado de la imagen de que ella había ingresado a la sala. Le escribí el primer mensaje rápidamente y así esperar la respuesta. Mi palpitar era semejante a los timbales de una orquesta, me retumbaba la cabeza. Sentí una emoción increíble cuando apareció la respuesta en la pantalla. El ordenador estaba escribiendo sólo, yo no estaba tecleando nada, eran palabras o frases animadas, como si tuvieran vida propia. Sentí que había transcurrido una enormidad de tiempo entre el envío del mensaje y la respuesta. Entonces imaginé en nuestro piso la habitación donde está el ordenador y me quedé con la imagen de verla sentada frente a la pantalla, mientras le volvía a contestar. En el apuro por escribir más rápido, se me escapaban muchos errores en el escrito y parece que a ella también, pero se demoraba tanto que apareciera la respuesta. En ese esperar, tanto ella como yo escribíamos lo que se nos iba ocurriendo, de tal manera que, sin darnos cuenta, habíamos generado un par de diálogos paralelos, que íbamos contestando a medida que aparecía la respuesta en la pantalla. Y los veinte minutos que habíamos acordado chatear se habían transformado en veinticinco, pero con tantas esperas en las respuestas, más bien había parecido un pellizco.

En comparación con el correo electrónico, el contraste era muy notorio. La respuesta, aunque se demoraba mucho más de lo que yo imaginaba, era cosa de esperarla y ahí estaba. La respuesta eran palabras animadas que aparecían secuencialmente en la pantalla. Había algo que hacía que esas frases fueran de ella, quizás su forma de preguntar o de contestar y el hecho de leer sus frases imaginando su entonación me resultaba muy distinto que leer lo que ella me escribía en el correo electrónico.

Hoy viernes tuve muchos problemas con la conexión del chat. No me había dado cuenta de que algunos ordenadores tenían conexión a Internet y otros a intranet. En estos últimos podías navegar dentro de la web de la universidad, pero con las otras direcciones de la web, la conexión era muy lenta. Yo estaba conectado a la misma hora de siempre, pero sentía que el ordenador andaba muy lento cuando me conecté a la web de emol.com. No me había dado cuenta de esta lentitud, pues estaba navegando dentro del campus de la universidad, donde la conexión andaba bien. Con mucha lentitud pudimos comunicarnos y brevemente le dije que el ordenador donde estaba tenía problemas y que nos escribíamos por correo electrónico. Sentí una desilusión tremenda y le pedí a uno de los encargados de la sala de informática que me explicara lo que me había sucedido. Entonces recién en ese momento pude darme cuenta de lo que había sucedido. Para chatear había que utilizar un ordenador que estuviera conectado a Internet y no a la intranet de la universidad. Además, el encargado de la sala me dijo que en los ordenadores de esta sala no se podían chatear, estaban al servicio de las actividades académicas de los alumnos de la facultad, no para actividades de ocio ni lúdicas. Esto me fastidió bastante, pues todos los días iba a la sala de informática, después de las clases de catalán, a revisar mi correo y siempre veía a muchos alumnos chateando. 


\section{Acerca de las llamadas por teléfono.}

Nuestra experiencia comunicándonos por teléfono fue gestándose poco a poco. Antes de comenzar el viaje, ninguno de los dos imaginó que el asunto de comunicarnos decantaría en que hablaríamos unos quince minutos casi todos los días. Aquello no estaba en los planes de ninguno de los dos:

... hoy sería la primera vez que hablaríamos por teléfono. Hasta ese momento, sólo nos habíamos comunicado por correo electrónico y por chat. Ya me estaba comenzando a fastidiar estos dos sistemas de comunicación. Yo le prometí que me encargaría de llamarla lo más seguido posible, pero lo que había conocido hasta el momento no me resultaba muy práctico. Decidí ocupar una tarjeta de Telefónica con chip, es decir, aquellas que tienen ese pequeño trozo rectangular color dorado por el anverso. ¡Fue un desastre! En realidad, aún no había preguntado mucho sobre cómo funcionaba el tema de las llamadas internacionales en esta ciudad. Algo había averiguado con el muchacho que trabajaba en una de las papelerías de la Vila Universitaria, pero no era mucho lo que sabía.

Aquella primera llamada fue un día sábado, por la tarde, como a eso de las ocho, pues en Chile serían las tres de la tarde. Fue desde una cabina pública de Telefónica de los ferrocarriles catalanes de Plaça Catalunya. Por la experiencia que tenemos en Chile con esta multinacional de telefonía, sabía que estaba colocándome a merced de un cobro brutal. Pero tenía tantas ganas de escucharla, que asumí la responsabilidad usar Telefónica para comunicarme. Hacía tres semanas que había aterrizado en Barcelona y sentía que la extrañaba muchísimo.

Escuchar su entonación cuando escuchó mi voz fue maravilloso, imaginé su cara y cómo se le ilumina su rostro cuando le suceden cosas así. Ambos estábamos muy emocionados, pues sólo nos habíamos comunicado por correo electrónico y por chat. Me parece que la llamada sólo duró unos cuatro minutos. Discar los números era sencillísimo, se utilizaba la misma lógica que en Chile: códigos internacional, de país, ciudad y el teléfono deseado. Efectivamente, el cobro era brutal, pagué el equivalente a cinco euros y no hablamos más de cinco minutos.

Recuerdo que nuestros tonos de voz se oían entre ansiosos y exaltados, ambos nos escuchábamos entre tensos, alegres y nerviosos. En algunos momentos nuestras voces se entrecortaban, había mucho ruido con la llegada y partida de los trenes. Cuando tocaron los timbres que avisan el fin de la llamada, ambos hablábamos más de prisa. Recuerdo que ninguno de los dos habló tranquilo, le prometí que seguiría buscando forma de comunicarnos por teléfono. Cuando colgué sentí la convicción que ni el chat ni el correo electrónico podían compararse con el teléfono. Había que encontrar la manera de hablar por teléfono de tal manera que yo pudiera pagarlo...

En el curso de catalán conocí a Jaime, un muchacho de México, que se comunicaba periódicamente con su esposa e hijos que estaban en la ciudad de Monterrey. Me recomendó la tarjeta Palticard, de la empresa IDT, que posteriormente encontré en la papelería de la Vila Universitaria, donde recibía los fax que mi madre me enviaba cuando aún ella no tenía instalado correo electrónico. Jaime me dijo que él llamaba a un número telefónico gratuito, luego los códigos y el número. Cuando le conté a mi compañera, se alegró mucho. Quedamos de hablar el domingo por teléfono, a las dos de la tarde, hora de Chile.

Aquel domingo hablamos telefónicamente con la tarjeta Platicard. Conversamos quince minutos aproximadamente, que se sintieron demasiado breves. Acordamos hablar los domingos, a la misma hora, y coordinarnos para hablar los miércoles en la mañana, antes de que ella se fuera al trabajo. 
Además, yo quería saber cuántas tarjetas necesitaría en el mes para hablar lo que habíamos acordado. Ella me dijo que me llamaría los días jueves por la tarde, hora de Barcelona. Había que ver cómo funcionaban en la prácticas nuestra organización.

Me había mudado de la Vila Universitaria y me había ido a vivir a la primera planta de una pequeña casa en Cerdanyola del Vallès. Una de las cosas que me había gustado era que el dueño, un muchacho brasilero, tenía teléfono fijo. Pero para sorpresa mía, cuando le expliqué cómo llamaba a Chile, se mostró dubitativo frente a marcar un número telefónico gratuito desde su línea. No me creía que los números que comenzaban con 900 eran números gratuitos. Tuve que llamar a Telefónica para cerciorarme de que así era. Me llamó mucho la atención, porque este muchacho brasilero tenía dos hijos que vivían en Sao Paulo y me dijo que los llamaba periódicamente. Cuando le pregunté que sistema utilizaba para llamar a sus hijos, me dijo que lo hacía directamente a través de Telefónica y que era muy caro. Me pareció muy extraño que alguien que llamara seguido a Brasil lo hiciera directamente a través de Telefónica, que de acuerdo a lo que me habían comentado, era el sistema más caro para llamar al extranjero. Bueno, cada uno sabe cómo gasta su dinero.

Hoy se me ocurrió preguntarle al A. por las tarjetas telefónicas mientras tomábamos café a media mañana. Él es un muchacho colombiano-venezolano que estudia el doctorado en psicología infantil. Nos habíamos conocido como usuarios de las cabinas individuales de la biblioteca de humanidades. Llegábamos todos los días muy tempranos por la mañana a esta biblioteca para así alcanzar una de las cabinas. En un par de ocasiones habíamos salido a tomarnos un café a media mañana junto a otros usuarios y usuarias de las cabinas. A. había llegado a Barcelona en septiembre de 2001, por tanto, llevaba prácticamente el mismo tiempo que yo llevaba en esta ciudad. Me comentó que él también utilizaba la tarjeta Platicard o la Latina, pero que a su país le daba muy pocos minutos la llamada. Cuando le pregunté por el funcionamiento de la llamada, me comentó que él llamaba a un número local dentro de Barcelona, es decir, había una llamada metropolitana, en horario económico, es decir, después de las seis de la tarde. Luego, ingresaba los números de la tarjeta, los códigos y el número. De esta manera, me comentó, obtenía más minutos que llamando desde el número gratuito. Me dijo que él había comprado una línea a Telefónica y que preguntando había llegado a conocer esta tarjeta. Aquel día me invitó a su piso para que probara cuántos minutos me daba la tarjeta para llamar a Chile. Fui a su piso como a eso de las ocho de la noche, después de la universidad, a ver cómo funcionaba la tarjeta. La diferencia entre llamar por el número gratuito respecto de llamar por el número local era muy significativa. Mi compañera estaba feliz cuando le conté. Por el cambio de hora, ella estaba en el trabajo, no sabía que yo la iba a llamar, era una genuina sorpresa. Entonces recién entendí los afiches que veía en los locutorios cuando iba a comparar las tarjetas. Había diferencias en la cantidad de minutos que entregaba la tarjeta, no sólo respecto del país al cual uno quisiera llamar, sino también desde el número desde el que se generaba la llamada. El mayor rendimiento lo entregaba la llamada local, es decir, lo que me había explicado mi amigo Aníbal, llamar en horario económico (después de las seis de la tarde) desde el teléfono de casa al 935.100.300, es decir, una llamada metropolitana, en el área de Barcelona, cuyo costo es muy bajo.

Al llegar a mi casa hablé con el dueño de la casa y le conté el asunto de las llamadas. Le propuse que probáramos, tanto con las llamadas a Brasil como con las llamadas a Chile, que yo asumía el costo de mis llamadas, pero él me dijo que él no tenía cómo separar las llamadas de él respecto de las mías. Me dijo que la cuenta llegaba por el total de las llamadas, por tanto, yo podía utilizar el teléfono para recibir llamadas o para hacer llamadas con el número gratuito. 
Hoy he decidido hablar con mi amigo A. por el uso del teléfono. En varias ocasiones él me ha ofrecido llamar a Chile desde el teléfono de su piso utilizando el número local de la tarjeta Platicard. El asunto es que esas llamadas son facturadas como llamada metropolitana. Antes de hablar con A. llamé a Telefónica para preguntar el costo de las llamadas metropolitanas en los horarios normal y económico. Entonces hice un cálculo y con cinco euros mensuales, podría llamar a mi compañera desde el piso del A. y así cubrir este gasto. Lo más importante de todo este asunto es que a ella la podría llamar más seguido. Hablar con ella es lo que más me gusta, mucho más que el chat y que el correo electrónico. Si yo la llamo cuando ella se está levantando, entonces podemos hablar tranquilos, aún cuando yo esté a cuatro o seis horas más que ella. Si intentamos hablar después que ella regrese a casa, entonces es más complejo coordinarse, sobretodo si ella tiene algo que hacer después de trabajar. Me siento más tranquilo cuando hablo con ella que cuando leo sus cartas electrónicas o sus respuestas en el chat. En este último me fastidia esa lentitud con que se suceden las respuestas, esa pereza con que aparecen las frases animadas. A pesar de las distancias, cuando hablamos por teléfono, la siento más cerca.

Me he dado cuenta que donde vivo, Cerdanyola del Vallès, hay varios locutorios cerca de donde vivo. Se parecen mucho a los centros de llamadas que hay en mi país. Llegué a ellos por casualidad, buscando tarjetas telefónicas, que antes las compraba en los estancos, pero como los locutorios están abiertos hasta más tarde los días laborales y siempre están abiertos los fines de semana. Me parece que los locutorios, a diferencia de los centros de llamadas de mi ciudad, tienen otros servicios además de las llamadas por teléfono. Aquí todos los locutorios tienen ordenadores conectados con internet, webcam, audífonos, servicio de envío de dinero, venta de varias tarjetas telefónicas. Pero al calcular los costos de las llamadas en comparación a la utilización de la tarjeta Platicard, marcando llamada local en horario económico, era mucho más económico que cualquiera de los locutorios que había cerca de mi piso. Si no tuviera acceso a la telefonía fija y sólo pudiera hacerlo por el móvil, entonces las llamadas al extranjero me compensaría ir a los locutorios. De hecho, me he fijado que algunos compañeros y compañeras de otros doctorados llaman a sus respectivos países a través de locutorios cuando no tienen teléfono fijo en el piso. Definitivamente, a mí no me conviene llamar a Chile a través de los locutorios.

Hoy he ido a Sitges, una hermosa playa que está al sur de Barcelona de fácil acceso en tren. A pocas calles de la estación había un pequeño locutorio que tenía la ventana llena de papales con el precio de las llamadas. Llamar por locutorios siempre es más caro que llamar por las tarjetas, siempre que uno llame utilizando la llamada local. Pero al pasar por la puerta me dieron ganas de llamarla de sorpresa, me dieron ganas de que escuchar aquella entonación con que me contesta cuando en horas en que no hemos acordado hablar. Calculé la diferencia horaria, y como estábamos a cuatro horas, estaría recién despertando. Y cuando la llamé contestó como yo esperaba que lo hiciera. Entonces le dije que, así como en la película de Matriz, apareciera por la cabina telefónica por la que estábamos hablando y fuéramos a tomar helados mientras paseamos por el paseo marítimo. Me contestó: "...encantada...".

Mi amigo H. me enseñó un truco muy interesante cuando uno está en la calle, necesitas hablar al extranjero y no hay locutorio cerca. Sólo había que encontrar una de las cabinas públicas de Telefónica, comprar una tarjeta de la misma Telefónica con chip y tener minutos en la tarjeta Platicard. Esta tarjeta del chip es la misma que utilicé la primera vez que llamé a mi compañera. Con esta tarjeta se paga la llamada local, utilizando la ranura horizontal del costado superior izquierdo que todas las cabinas de Telefónica tienen para sus tarjetas prepagadas. Luego se marca el número local 
de Platicard y listo. Lo interesante es que el costo global de la llamada continuaba siendo más barato que la llamada desde los locutorios, pero más cara que llamar desde el teléfono del piso. Aún así, esta ingeniosa mezcla, probada por mi amigo H., permitía resolver uno de los inconvenientes más desagradables del cambio horario con mi país: el querer hablar cuando uno está fuera de casa.

Mi compañera me ha llamado para contarme de que hay dos empresas de "carrier" que le están ofreciendo tarifas preferenciales, a través de distintos contratos, para llamar a España. Los "carrier" son empresas que venden los servicios de llamadas nacionales, internacionales y de internet. En la factura del teléfono viene detallada la utilización de los "carrier". Cada "carrier" se identifica con un número de tres cifras. Éste tiene que ser marcado al inicio de la llamada, luego el 00, luego el código de país, el de ciudad y el número. Mi compañera me dijo que había preguntado cuál carrier tenía la tarifa más económica a España y que con ellos me estaba llamando. Pero aquí ocurrió algo curioso. Ella me dijo que la llamaron de tres carrier para ofrecerle tarifas más baratas, siempre que ella firmara un plan con ellos. No había que preocuparse de nada, ellos enviaban a su gente a la oficina para firmar el plan. ¿Cómo las distintas compañías de carrier saben que una persona está llamando al extranjero?. ¿Cómo saben que estoy utilizando el carrier de la competencia?. El asunto es que se generó una pequeña, pero interesante disputa entre estas tres compañías de carrier. Mi compañera tuvo la posibilidad de negociar el cargo fijo, el valor del minuto de la llamada y la diferencia de tarifas cuando el destino de la llamada era un número local o un móvil. El asunto es que ahora, ella tenía la posibilidad de llamarme más seguido utilizando prácticamente la misma cantidad de dinero que estaba gastando hasta el momento.

Hoy ha sido uno de esos días en que cuando la llamo a la hora que se despierta por la mañana está tan cansada que su adormilamiento apenas nos permiten hablar un poco. Le digo que la llamo más tarde al trabajo, aunque ambos sabemos que es más difícil hablar desde su oficina. Entonces me dice que no, que hablemos ahora porque cuando llegue a la oficina tendrá gente para entrevistar. Le propongo que la llamo en una hora más, antes de partir a la oficina. Entonces me dice que no porque se va a levantar justo para llegar a la hora al trabajo. Y así se va el poco tiempo que tenemos para hablar. Es un desastre, porque me quedo con la sensación de que no he hablado con ella, y cuando esta situación se repite varios días seguidos, me comienzo a entristecer y a preocupar. Está trabajando mucho, descansado poco y comiendo un par de veces al día. Y no es mucho lo que puedo hacer, tratar de llamarla a la oficina a la hora del almuerzo o en algún momento en que no haya gente. $Y$ cuando logro comunicarme con ella, escucho su voz escucho con muy pocas inflexiones en su entonación, o bien ésta pareciera adquirir matices de fastidio, entonces se escucha como si le desagradara con quien está hablando y sus frases suelen ser muy breves, apagadas. Al colgar me quedo con la misma sensación de no haber hablado con ella. Aún cuando sepa que está con mucho trabajo y que hay temporadas que su trabajo es así, la extraño aún más y más...

Hoy ha sido la conversación de los bostezos. Es más bien un intento de comunicarse, ya que el resultado es frustrante. No me cuenta nada si no se lo pregunto, y sus respuestas son en extremo vagas o breves. Estaba escuchando televisión, ni siquiera sabía lo que estaban dando, estaba algo adormilada con el volumen un poco más alto para no quedarse dormida y así poder descansar bien por la noche para arrancar bien el lunes. Fue más bien una pseudoconversación constantemente interrumpida por los bostezos, que no me permiten entenderle nada. Su voz se escucha con matices de lacidez y ternura, matices que no se alcanzan a definir por completo. Y los bostezos, inoportunos, me resultan muy desagradables, cortan la conversación: "...la última parte no te entendí nada con tanto bostezo...". Son los períodos de trabajo en que termina la semana tan extenuada, que las horas 
de sueño de cada noche y los fines de semana no le son suficientes para que pueda recuperarse. Cuando contesta, su entonación la delata y los bostezos no se hacen esperar. Entonces vienen las banalidades y comienza el interrogatorio: si no le pregunto, pues no cuenta nada. Y los bostezos, hacen que la conversación resulte muy poco fluida. Siento mucha pena e impotencia cuando la escucho así, no es mucho lo que puedo hacer.

Hace unos pocos días me ha sucedido algo curioso: cuando llamé a mi compañera abrí una tarjeta nueva y al ingresar los números de ésta, la grabación dice que tengo cinco euros disponibles y que para el número que he marcado tengo cuatro horas y cincuenta minutos. Yo recordaba que los cinco euros rendían tres horas y cincuenta minutos a Santiago de Chile. Después de hablar con ella, le pregunté a quienes conocía lo que me había sucedido, pero a nadie le había pasado. Al día siguiente me volvió a suceder y le conté mi compañera lo que me estaba sucediendo. La grabación volvió a decirme que tenía cerca de cuatro horas y cincuenta y dos minutos para el número que había marcado. Ella estaba contenta, eso significaba que podríamos hablar más minutos en cada llamada. Al parecer la tarjeta había aumentado los minutos para todos sus destinos sin subir valor de la misma, pero a través del número de atención al cliente es muy difícil lograr comunicarse. Hay que llamar después de las doce del día y casi siempre la llamada finaliza sin que nadie de la empresa responda. Lo concreto es que de a poco pude ir corroborando, a través de la gente que conocía, que la tarjeta había aumentado los minutos a sus destinos sin aumentar el valor de la tarjeta. Ella estaba muy contenta, ahora podíamos hablar más tiempo sin que tuviera que pagar por ello. ¿Será alguna estrategia de mercado para que los usuarios de las tarjetas prefiramos la Platicard?

\section{Acerca de los billetes de avión por internet.}

M.J. y P. son una pareja de compatriotas que están haciendo el mismo doctorado que yo. Ayer estuve conversando con ellos y me contaron que viajarían a Chile a pasar navidad y año nuevo. Yo les conté que viajaría a Zürich, a casa de una prima de mi compañera. Ellos habían conseguido un par de billetes en Iberia, ida y vuelta, en una oferta que sólo se podía comprar por Internet. Eran billetes sólo por treinta días.

Mientras volvía a casa, me quedé pensando en esta posibilidad. Juntar 600 euros en siete meses, era posible, pues el cambio está casi a la par.

Hoy fui a preguntar a las dos agencias de viajes que hay en la Plaza Cívica de la universidad. La del RACC no vendía billetes a sudamérica, pero la Unlimited tenía varias posibilidades en distintas aerolíneas. El billete más económico era en Lufthansa y era un billete por tres meses. Eso significaba que podría ir a Chile durante el verano europeo. Claro que tendría que pagarlo al contado o con tarjeta de crédito. Entonces fui a la oficina de mi banco para tramitar una tarjeta de débito y poder pagar con Visa Electrón. Una vez que me entregaran la tarjeta de residencia (el visado), podría obtener esta tarjeta. Luego fui al Internet a ver la oferta que P. y M.J. habían comprado en Iberia. Pero no encontré billetes a Chile con las características que me ofrecían en la agencia Unlimited. Las ofertas que estos últimos disponían eran muy superiores a las ofrecidas por la web. 


\section{Acerca de nuestra experiencia con la webcam}

Ese día que nos íbamos a conectar por la webcam me sentía super expectante, íbamos a poder hablar y vernos, simultáneamente, iqué guai!, como se dice en este país. Ella me había contado que en su trabajo habían contratado ADSL y comprado una webcam. Lo había estado probando y me dijo que era muy sencillo, sólo necesitábamos el Messenger. Pero no elegí bien el locutorio, pues aún cuando tenía webcam, no sabía que los Messenger, de ambos interlocutores tienen que estar actualizados con la misma versión de este programa. Entonces fue un desastre, porque sólo pudimos chatear, y como aquello lo siento horriblemente lento, me pone rápidamente mal genio. Ella no tenía mucho tiempo y había que esperar que el ordenador donde yo estaba actualizara la versión, pero mi bonita no podía esperar tanto. ¡Ese colegio donde trabaja me fastidia cada día más! Yo me había hecho la ilusión de verla y no se pudo. Volví a casa mal genio, desilusionado, caminando por las calles que me condujeran al locutorio "La Paz". Aquí sí tenían lo que necesitaba, recordaba, vagamente, alguna vez que lo utilicé, que tenían webcam y XP. Cuando llegué al piso la llamé y le dije que podíamos intentar nuevamente en este locutorio. Quedamos para hacer un nuevo intento, ahora desde el locutorio "La Paz".

Afortunadamente aquel día me espavilé y llevé el móvil. Iba igual de expectante que la vez anterior, mirando la hora, imaginando cómo sería esto de vernos por la web. Cuando me estaba conectando, suena mi móvil. El ordenador del colegio lo estaban ocupando con un trabajo urgente y había que esperar quince minutos más. ¡Uf....qué joda..... Me quedé navegando, sintiendo minutos eternos, leyendo la prensa online de mi país. Me estaba conectando nuevamente cuando nuevamente sonó mi móvil: estábamos listos. Mi palpitar era muy sonoro, la conexión me parecía lenta, aún cuando me habían dicho que se trataba de ADSL. Cuando presioné la tecla de la cámara, ella apareció, y yo también, en un recuadro más pequeño. ¿Qué maravilla!. Estos son los momentos en que amo a la tecnología. Previo a la conexión, le había pedido al dependiente que me ayudara con la rutina de ventanas de la conexión. Le pregunté rápidamente si se podía mejorar esa calidad de la imagen y me preguntó si ella también tenía ADSL, XP y todo lo demás. Cuando le dije que sí, me dijo que era lo mejor que se podía ver. ¡Joder, se veía bastante mal la imagen, como estática!. Le había crecido el pelo, la chasquilla estaba más larga que para vacaciones de navidad, se veía con cara de fastidiada y gesticulaba, pero la resolución de la cámara no me permitía entender lo que estaba haciendo.

Le pregunté por el audífono y el citófono, pero me dijo que lo habían desconectado, que no sabía qué pasaba. Hasta ese momento habíamos utilizado lo mismo que el chat. ¡Uf...qué fastidio...esto de chatear es horriblemente lento!. Hay que estar esperando la respuesta, salvo que quieras mantener dos conversaciones paralelas. Pero bueno, iqué diablos!, es lo que hay. Igual me sentía contento de verla, le pregunté por su cara de fastidio. Me dijo que en el colegio siempre anda así. Imaginé algunas conversaciones anteriores cuando en que me ha contado que la dueña del colegio ha contratado mucha gente mediocre y que eso la tiene fastidiada.

La resolución de la cámara tampoco me permitía mirarla a los ojos, la expresión de sus ojos, las imágenes se veían entrecortadas, incluso, en ciertas ocasiones, bastante borrosos. ¡Qué desilusión!. Era parecida a una película de Chaplin. Le pregunté si ella me veía así de borroso como yo la veía. Me dijo que sí, que también me veía con poca resolución y muy entrecortado. Yo pensaba que se vería mejor, más definido, más cerca... Nada de eso, además los audífonos de su ordenador no estaban conectados y había que interrumpir constantemente la comunicación cuando sonaba el teléfono del colegio o cuando alguien entraba a la secretaría. Pero aún así la podía ver, en un 
momento se retira de la mesa para entregar un documento, o algo así a una persona que entra en la oficina.

Recuerdo que cuando llegué a Barcelona, una de las cosas que tenía muy presente en hacer era curiosear en esto de las comunicaciones. Yo imaginaba que esto era más sencillo, más accesible. Pensaba que teniendo una webcam y una simple conexión vía modem, ya podrías tener imagen y sonido. Pero el tema no iba así: las conexiones vía modem con webacam tenían muy baja calidad, especialmente en las horas de mucho tráfico y el ADSL era muy caro todavía. Con el portátil que tenía, me faltaba casi todo: RAM, modem más veloz, webcam, horas de poco tráfico. Muchas condiciones para un estudiante de doctorado de presupuesto moderado: ... hoy fui al centro de Barcelona por unos trámites, pasé a curiosear por uno de los cybercafé que están cerca de la Plaça Catalunya, de esos que frecuentan los turistas. Compré una hora de navegación y me di cuenta de que había gente que estaba utilizando las webcam. Me llamó la atención que hablaban por un micrófono y escuchaban por unos audífonos, como los que utilizan las telefonistas. Me fijé que no utilizaban el teclado para nada. Hablaban como si estuvieran en una cabina telefónica, pero además, podían ver a su interlocutor por medio de la webcam. ¡Qué fantástico!. Le pregunté al encargado cómo era funcionaba este sistema de comunicación. Me explicó que era sencillo, ambos interlocutores necesitaban de una webcam, del Messenger y de preferencia una conexión ADSL, ya que con la conexión a través de modem las imágenes se veían como fotografías. Me dijo que viniera un día sábado por la tarde, pues ese día trabajaba un muchacho que enseñaba a comunicarse por medio de la webcam. El asunto es que mi compañera no tenía nada de esto y el sistema de ADSL había sido estrenado hacía poco tiempo en mi ciudad, por lo tanto, aún era un servicio muy costoso. Recuerdo que en el supermercado cerca de nuestro piso hay un cybercafé que tenía ordenadores con webcam. Tendríamos que organizarnos para poder vernos a través de la webcam, pero reconozco que es muy poco funcional para ambos: yo tengo que ir a un a un cybercafé o un locutorio, lo que no es tan complicado para mí, pero el hecho de que ella tenga que ir a un cybercafé, limita la comunicación sólo a los fines de semana y en estos días ella hace lo que no puede hacer durante la semana. Para ella esto e muy poco funcional...

Cuando regresé de las vacaciones de verano, mi amigo A. se había comprado una pequeña webcam compatible con su ordenador portátil. Quería comunicarse con sus hijos en Venezuela a través de internet, pues las tarjetas telefónicas le daban muy pocos minutos, aún cuando llamaba a través del número local y en horario económico. Los hijos irían a casa de una compañera de trabajo que tenía ordenador con webcam. Me llamó la atención que comprara una webcam, ya que en más de alguna oportunidad habíamos conversado que, aparentemente, se requería de una conexión ADSL para que hubiera una buena comunicación. Me dijo que tenía que navegar en horarios de poco tráfico para poder hablar con sus hijos, pero la resolución de la imagen era muy mala. Con esta experiencia, no había más que sepultar la idea de regalarle una webcam a mi compañera para el ordenador de casa. La conexión por ADSL aún es muy costosa en nuestra ciudad, por lo tanto, tendría que conectarse a través vía modem. Aún no conocía a nadie que, utilizando este tipo de conexión, pudiera conectarse con la webcam sin tener alguna clase de problemas. Aún cuando yo pudiera conectarme por ADSL, para mi compañera el tema seguía siendo muy poco funcional.

Recordando y escribiendo estas líneas me he visto saludando a mi compañera con aquella entonación con que mi abuelito saludaba a mi abuelita. Berti::ta mí:::a- él le decía, y ella se ponía contenta; -boni::ta mí::.:a-, le digo cuando la llamo, y ella contesta -sí::.::? mmhhh-. 


\section{Referencias}

Reed-Danahay, D.E. (1997). Auto/Ethnography. Rewriting the Self and the Social. Oxford: Berg.

Velasco, H. y Díaz de Rada, A. (1997). La lógica de la investigación etnográfica. Madrid: Trotta.

\section{Formato de citación}

Lewin, J.G. (2004). Cuándo el océano ya no es la última frontera: una relación a (muy) larga distancia a través de las TICs. Athenea Digital, 6. Referencia disponible en http://antalya.uab.es/athenea/num6/lewin.pdf

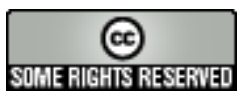

Este texto está protegido por una licencia Creative Commons.

Usted es libre de copiar, distribuir, exhibir y comunicar la obra bajo las siguientes condiciones:

Reconocimiento: Vd. debe reconocer y dar crédito al autor original.

NoComercial. Vd. no puede utilizar esta obra para fines comerciales.

NoDerivados. Vd. no puede alterar, transformar, o añadir nada a esta obra.

\section{$\underline{\text { Resumen de licencia }}$}

$\underline{T e x t o ~ c o m p l e t o ~ d e ~ l a ~ l i c e n c i a ~}$ 